greatest weight with all who read it, has made me feel the importance of entering a note of dissent in a matter which I, for one, believe to be of great clinical importance. If I have in any way misunderstood, or quite unwillingly and unintentionally misrepresented Priestley Smith's views, I trust that he will at once correct me, and I shall tender my amplest apologies.

The question, as I understand it, is: Have we in the McLean tonometer an accurate instrument whereby we can measure the intraocular pressure with the same accuracy as we estimate body temperature with the clinical thermometer?' I have been using this instrument side by side with my trusted Schiötz tonometer for some weeks past, and 1 think we have. The only outstanding question to my mind lies in the explanation we are going to accept as to the difference between McLean's pressures and those of Schiötz and Smith. Be it remembered that McLean is offering no new estimate of the normal intraocular pressure, but is rather going back to the older estimates which we accepted before our ideas were upset by the advent of the valuable Schiötz instrument. Yours, etc.,

LonDon, W., July 19, 1919.

R. H. Elliot, Lt.-Col. I.M.S. (Ret.)

\title{
PEDUNCULATED HAEMANGEIOMA OF CONJUNCTIVA
}

\section{To the Editor, British Journal of Ophthalmology.}

SIR,-On looking through back numbers of the BRITISH JOURNAL OF OPHTHALMOLOGY, published during my absence abroad, I notice in the Journal for March, 1918, a paper by Messrs. Rutson James and R. S. Trevor, on haemangeioma of the palpebral conjunctiva. They describe two cases of this condition in which the growth formed a pedicled tumour, both of them occurring in youths. They state that references to such tumours in ophthalmic literature are very few, and they were only able to find references to some six other cases, four of which are taken from foreign literature. It may interest, therefore, the authors of this paper to learn a few details of a case that occurred five years ago in my practice in Norwich, especially as the patient was a man aged about 55 years, for all the previously recorded cases in this country were youths of 20 years or under.

The only symptom my patient had was that of occasional slight "bleeding from the lid" for about three months before consulting me; in this respect it differs from the authors' two cases, one of 
which complained of a lump on the lid, and the other of defective sight, but neither of them had any haemorrhage from the tumour.

On everting this patient's left upper lid, a small pedicled tumour the size of a pea was at once seen, growing from the surface of the palpebral conjunctiva, mid-way between the upper fornix and the lid margin and slightly towards the nasal side; the tumour looked vascular and semi-transparent, was flattened from before backwards and was freely movable on its pedicle: there was no general conjunctival hyperaemia, nor any excessive lacrymation.

The tumour was snipped off with scissors and its base cauterized with silver nitrate stick. Dr. Claridge kindly cut a section of the tumour for me and reported as follows: "It consists of a collection of capillaries with a very small amount of connective tissue, and is evidently a capillary angeioma or naevus."

On looking at the slide after reading Messrs. James and Trevor's communication on the subject, one can see with the naked eye that it is a pedunculated tumour enclosed in a capsule; its appearance is remarkably similar to the illustration of the section appearing in the paper in question, except that I do not see any pigment in any part of the slide. If the surviving author of the communication above referred to would care to see the section, I shall be pleased to send it to him.

Yours, etc.,

NoRWICH, July 9, 1919.

G. MAXTED.

\section{MYOPIA}

To the Editor, British Journal of Ophthalmology.

SIR,-Dr. Thomson's paper in your July issue recalls some tork* I did on this subject years ago. He deals with children only, and while his numbers are small it is interesting to observe that he breaks away from the blind continuity of text-book tradition.

Anyone interested should study the laws of heredity, for myopia exhibits an interesting sex limitation, but this can only be brought out when large numbers are dealt with.

Yours, etc.,

The LORD DERBY War Hospital, Warrington.

$$
\text { J. A. Wilson. }
$$

July 5, 1919.

*" The Factor of Heredity in Myopia," British Medical Journal, August 29, 1914. 